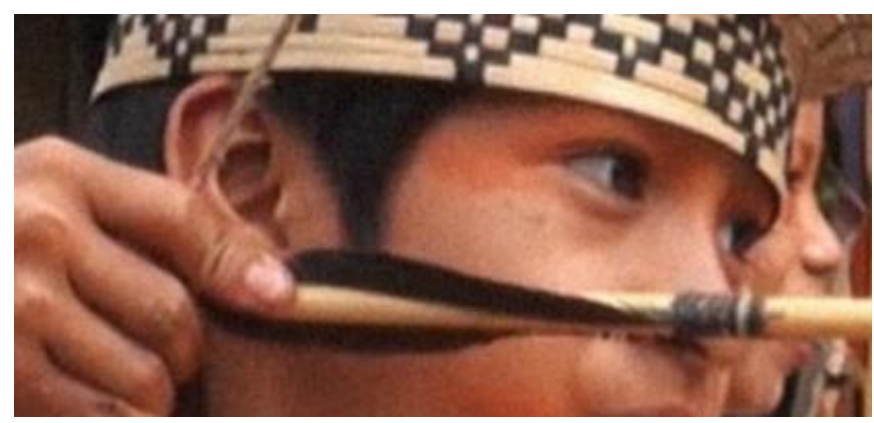

\title{
Um olhar discursivo sobre o processo de subjetivação do indígena em dispositivo didático
}

A discursive view on the process of subjectivation of the indigenous in didactic device

\author{
Icléia Caires Moreira ${ }^{1}$ \\ https://orcid.org/0000-0002-1572-8630 \\ Vânia Maria Lescano Guerra² \\ https://orcid.org/0000-0001-8361-2106
}

\begin{abstract}
Resumo:
A partir de um olhar discursivo-desconstrutivo sobre o Guia Didático "Cineastas Indígenas para Jovens e Crianças", este artigo problematiza os efeitos de sentido de in-exclusão dos sujeitos indígenas das etnias Wjãpi, Ikpeng, Panará, Ashaninka, Mbya-guarani e Kisêdjê, que emergem desse texto produzido pela OnG "Vídeos nas Aldeias" e publicizado no ciberespaço. Pautamonos, transdisciplinarmente, na Análise do Discurso de origem francesa (PÊCHEUX, 1988), na arqueogenealogia foucaultiana (2014) e no pós-colonialismo (CASTRO-GÓMES, 2005; BHABHA, 2013). Nossa hipótese é a de que a representação identitária desses indígenas ocorre via discurso da sociedade hegemônica (branco), como um processo de subjetivação/identificação dos indígenas. Reflexões iniciais apontam que o discurso subjetiva esses sujeitos (re)legando-lhes ao entre-lugar da in/exclusão e da construção estereotipada de suas identidades na contemporaneidade.
\end{abstract}

Palavras Chave: Guia didático. Subjetividade. Povos Indígenas.

Abstract:

From a discursive-deconstructive view on the Didactic Guide "Indígennous filmmakers for the young and the children", this research problematizes the effects of sense of in-exclusion of the indigenous subjects of the Wjãpi, Ikpeng, Panará, Ashaninka, Mbya-Guarani and Kisêdjê ethnicities, which emerge from this text produced by the NGO "Videos in the Villages" and publicized in cyberspace. We discuss, in a transdisciplinary way, the Discourse Analysis of French origin (PÊCHEUX, 1988), in Foucaultian archeogenealogy (2014) and in postcolonialism (CASTRO-GÓMES, 2005; BHABHA, 2013). Our hypothesis is that the identity representation of these indigenous people occurs through a discourse of hegemonic society (white), as a process of subjectivation/identification of indigenous people. Initial reflections point out that the discourse submits these subjects (re) bequeathing them to the inplace of the in / exclusion and the stereotyped construction of their identities in the contemporaneity.

Keywords: Didactic guide. Subjectivity. Indigenous people.

\footnotetext{
${ }^{1}$ Doutoranda em Estudos Linguísticos na Universidade Federal de Mato Grosso do Sul (UFMS/CPTL), bolsista da FUNDECT. Mestre em Estudos Linguísticos pela mesma instituição. E-mail: icamoreira@hotmail.com.

${ }^{2}$ Docente do Programa de Pós-graduação em Letras da Universidade Federal de Mato Grosso do Sul (CPTL); Doutora em Linguística pela UNESPde Araraquara, com Pós-doutorado em Linguística Aplicada pela UNICAMP (IEL). E-mail: vguerra1 @ terra.com.br.
} 


\section{Introdução}

A frequente alusão à obrigatoriedade do ensino-aprendizagem da "História e Cultura indígenas", nas instituições escolares, viabilizada pela lei 11.645 /08 promulgada pelo governo brasileiro em 10 de março de 2008, como um objetivo educacional a ser cumprido, aponta para um discurso atual a respeito da inclusão das minorias marginalizadas e se vale da educação como um caminho fomentador deste processo. Esta conjuntura, acima delineada, instigou-nos, enquanto analistas do discurso, a investigar sobre o assunto em busca de respostas para questões como: O que significa ser indígena hoje? É possível ensinar via dispositivo didático quem são e como vivem? O que significa ter uma identidade? Como ela se erige? Por qual voz? Quais efeitos de sentido o uso das (novas) tecnologias produzem nesse cenário de constituição e formalização de um saber sobre o outro?

Para responder e problematizar tais questões, esta pesquisa erigiu seu corpus a partir de recortes discursivos extraídos do Guia Didático "Cineastas indígenas para jovens e crianças" (CIPJC), material produzido com auxílio das (novas) tecnologias (áudio-visuais) pela Ong Vídeos nas Aldeias (VNA), publicado em 2010 e publicizado no ciberespaço para download gratuito.

Pautados, transdisciplinarmente, na perspectiva da Análise do Discurso de origem francesa (AD), a partir de PÊCHEUX (1988,1997), no artifício arqueogenealógico foucaultiano (2013a, 2013b, 2014) e na visada Pós-colonialista (CASTRO-GÓMES, 2005; BHABHA, 2013; MIGNOLO, 2003), partimos da hipótese de que a representação identitária do indígena ocorre via discurso do branco, como um processo de subjetivação/identificação do indígena, mediante o uso das (novas) tecnologias.

Temos por objetivo geral problematizar os possíveis efeitos de sentido de in/exclusão do indígena, emergidos desse arquivo. E adentrar, especificamente, nessa rede discursiva, voltada ao ensino fundamental, para analisar as imagens construídas a respeito do indígena e da sua cultura perante a sociedade.

A relevância em se analisar CIPJC advém do fato deste material se inserir no rol de acontecimentos discursivos do campo educacional vinculados ao saber sobre o indígena e suas culturas, que ocorre na contemporaneidade, além de contribuir para o debate sobre esse tipo de produção didática, abordando-o como um dispositivo de saber- 
poder que se estabelece com especificidade e originalidade nesse campo do conhecimento.

Vale dizer que neste artigo, ora trazido a público, mobilizamos uma amostra de um projeto mais amplo, a partir da incursão analítica de um dos recortes eleitos, em decorrência dos limites materiais, tanto do tempo quanto do espaço.

\section{Dimensões históricas e suas implicações no/sobre o discurso didático a respeito dos indígenas.}

Ao tratar da temática indígena e suas (inter)relações com o material didático em análise, é preponderante levantar as nuances históricas responsáveis pelo modo como o indígena tem sido retratado no discurso didático, no bojo de conjunturas que remetem a acontecimentos enunciativos próprios dos jogos de poder e que relegaram ao indígena uma posição estereotipada na esfera social.

Segundo Marques e Souza (2008), a história dos povos indígenas está marcada pela chegada dos lusitanos ao Brasil, cuja influência delineou e modificou o curso de suas vidas. Uma história construída pelo viés da unilateralidade, repleta de versões, contradições, mediante escassa documentação escrita, visual e oral, o que poderia contribuir para a "dissimulação" da "verdade" no que tange à (re)construção da história dos grupos indígenas.

Os estudos semioticistas de Limberti (2009-2012) apontam que desde a Carta de Pero Vaz de Caminha, aqui compreendida como discurso fundador, é possível notar que os traços delineadores da identidade dos indígenas ocorreram e continuam a ocorrer pela voz do outro, do branco (LIMBERTI, 2009, p.22): "branco" para designar todos os sujeitos que não pertencem a etnias indígenas, em um processo de apropriação e manipulação dos sentidos.

No decorrer da História, essa matriz representativa sobre o indígena ecoa no imaginário social, via práticas de linguagem, e se realiza em diversas materialidades (livros, fotografias, vídeos). E por mais que essas materialidades se revelem "completas", trazem, no bojo de sua constituição, apenas rastros da "real história"; portanto, são interpretações que a cada atualização (enunciação) a(e)nuncia um discurso sobre o sujeito indígena mas, simultaneamente, realiza o apagamento necessário para que o discurso histórico sobre o indígena possa continuar a ser (re)produzido.

Tanto que ao se falar em indígenas no Brasil emergem, pela/na memória discursiva, alguns aspectos que o caracteriza(ra)m de forma emblemática: a questão 
colonial, a visão dos indígenas como seres de sociedades baseadas em sistemas primitivos, sua inextrincável relação com a natureza e o exótico permeado de adornos e pinturas, bem como a condição de aldeados sempre remetida a falta de civilidade (GUERRA, 2010).

E é a partir desse cenário histórico-social e ideológico, que "surge" o CIPJC, em 2010, patrocinado pela Unesco e pela embaixada da Noruega, como dispositivo, prática discursiva, propagador(a) das "Histórias e Culturas Indígenas", no cenário educacional brasileiro, sob o manto da orientação legal vinculada às políticas inclusivas relativas à diversidade cultural. Mobilização que insurge das assertivas discutidas na Conferência Geral da Organização das Nações Unidas para Educação, Ciência e Cultura, em sua 33a reunião, celebrada em Paris, de 03 a 21 de outubro de 2005, ratificada pelo Brasil em 2006.

Como resposta às decisões articuladas nessa Conferência, promulgou-se em 10/03/2008 a lei 11.645, que veio alterar a legislação vigente em busca de adequações da Lei $\mathrm{n}^{\circ}$ 9.394, de 20 de dezembro de 1996, estabelecedora das diretrizes e bases da educação nacional, já alterada em 9 de janeiro de 2003 pela Lei nº 10.639 (articuladora da obrigatoriedade do ensino de Histórias e culturas afro-brasileiras nas escolas de ensino regular), para incluir no currículo oficial o ensino básico, como mais um desdobramento da inclusão das minorias marginalizadas, a "História e Cultura Indígena".

O CIPJC se constitui como um desdobramento das iniciativas empreendidas pela Ong Vídeo nas Aldeias (VNA), que se lançou na tarefa da escrita pedagogizante, no desejo de produzir sentidos no âmbito impresso, audiovisual e virtual sobre os indígenas. Trata-se de um guia didático e de uma seleção de seis filmes que traz informações de seis povos: Wjãpi, Ikpeng, Panará, Ashaninka, Mbya-guarani e kisêdjê. Segundo informações disponíveis no site da Ong, as seis etnias foram escolhidas por participarem do projeto Vídeo as Aldeias que oferece formação audiovisual em algumas comunidades indígenas, em sua maioria, localizadas no Acre, Pará, Amapá, Tocantins, Mato Grosso, Paraná, Santa Catarina e Rio Grande do Sul. Trata-se de um tipo de gênero didático que se marca pela veiculação de saberes, abalizando "o que e como se ensina" dentro do cenário educacional.

Este material está disponível em dois formatos virtuais: PDF ou cópia digital interativa, ambos alocados no ciberespaço por meio de links hospedados no site da Ong 
VNA. O dispositivo versa sobre o universo infantil indígena, territórios, mitos, cotidiano, problemas e brincadeiras. Sua disponibilização na internet é uma forma de divulgação da iniciativa, estratégia para despertar interesse do MEC ou secretarias Estaduais/Municipais de Educação que desejem reproduzi-lo e implementá-lo na rede escolar como uma forma de amparar didaticamente o ensino das Histórias e culturas indígenas em sala de aula.

Esse processo de publicização do material, no ciberespaço, converge para uma ação de inclusão ainda mais ampliada, proporciona a universalização do conteúdo por meio do acesso à rede de modo global. Observa-se aí que o CIPJC almeja a produção de uma identidade integrativa para os indígenas capaz de se expandir para além dos limites escolares, por meio do advento tecnológico e suas ferramentas tangíveis e intangíveis.

Na esteira de Lèvy (1993), podemos dizer que o discurso pedagógico sobre o indígena, ao ser digitalizado, passa pelo processo de virtualização, que permite sua (de)composição, (re)composição, (in)dexação, além da inserção de comentários, colagens, (re)empregos. Ramificando-se e difundindo-se em várias direções e usos dentro da rede. Dessa forma, o aparato didático digital tem seu conteúdo transfigurado em um grau de plasticidade inerente à escrita virtual, principal ferramenta tecnológica intelectual da atualidade.

Conforme Castells (2007), a estrutura social de uma sociedade em rede (globais) é produto do processo interativo entre o paradigma da (nova) tecnologia e a organização social. Sua grande vantagem advém da possibilidade de as pessoas terem acesso umas às outras, de difundirem, no nível mundial, bens, serviços, comunicação, informação, ciência e tecnologia. No ciberespaço, cada sujeito encontra sua maneira de promover a cultura e a arte do fazer em conjunto, uma maneira de dar visibilidade ao que se deseja. (COUTO, 2014, p. 282.)

Convém ressaltar que os sujeitos indígenas também estão submetidos ao processo de subjetivação, intrínseco a produção dos artefatos audiovisuais de caráter pedagogizante, (entre)tecidos ao espectro do consenso político, para garantir, na ilusão de integração social, a manutenção dos traços culturais de suas etnias no bojo da sociedade.

Nesse processo, vê-se que o grupo outrora considerado "discriminado", paradoxalmente, repudia e internaliza regras e costumes do outro, fator justificado pelo instinto de preservação cultural. O sujeito indígena vê-se na situação de aceitar hábitos da cultura hegemônica para não sucumbir, para permanecer (LIMBERTI, 2008). 
Nessa esteira, é possível analisar como se constitui as nuances iniciais da imagem que o outro, o branco, estabeleceu do indígena, fundamentada no espectro, no rastro colonial que ainda ecoa nos ditos sobre esses sujeitos na atualidade. E é dessa maneira que se pode balizar como os discursos, na sociedade, sobre o indígena, têm se constituído como saber sobre o outro, mecanismos de poder no interior dos próprios discursos científicos, neste caso o pedagógico, que vem ditar, em certa época, a qual regra somos obrigados a obedecer sobre a vida, sobre a história dos indígenas e naturalizá-la como uma verdade.

\section{Balizagens teóricas transdisciplinares: possíveis articulações}

É consensual entre estudiosos da Análise do Discurso que Sujeito e Sentido constituem-se em concomitância, pois o sujeito ao significar, significa-se. Da interpelação do indivíduo, afetado pela língua e pela ideologia, desencadeia uma forma sujeito histórica, materializada discursivamente, produtora de gestos de interpretação, modos de interferir e de ser interferido por outros sujeitos no mundo, via prática simbólica e social.

Esse sujeito é, por sua vez, descentrado, cindido, clivado e ocupa "lugares determinados na estrutura de uma formação social” (PÊCHEUX, 1997, p. 82), sendo caracterizado por dois esquecimentos: no primeiro, crê, ilusoriamente, ser origem do dizer, sem considerar que se constitui de inúmeras vozes precedentes; no segundo, esquece-se de que não controla os efeitos de seu dizer, e crê na monossemia de seu discurso.

Em interface com os estudos foucaultianos, vemos que a noção de sujeito se configura como pluralidade de posições e funções possíveis. Ao nascermos, somos inseridos no mundo da linguagem de maneira a ocupar um espaço perpassado de diversos dizeres que nos precedem (o interdiscurso). É a partir desse/nesse campo simbólico que se estabelecem os "lugares" para o sujeito, espaços complexos e dinâmicos de relações microcapilares de poder onde são construídas posições possíveis de serem ocupadas.

É da relação entre o poder e o saber, do exercício das relações de poder sobre um indivíduo que se produz um saber sobre ele. Disso decorre o que chamamos de subjetivação, o produto do exercício de poder que se constitui dos processos de 
objetivação do indivíduo. As relações de poder (in)(en)formam práticas das quais emergem discursos, em um procedimento circular, altamente produtivo, em que emerge a fabricação das subjetividades.

Foucault (2015, p.12), valendo-se da política da verdade, explica que as relações de força e relações políticas são as condições geradoras da possibilidade de formação de um certo número de domínios de saberes tidos como verdades: "a verdade é deste mundo; ela é produzida nele graças a múltiplas coerções e nele produz efeitos regulamentados de poder. Cada sociedade tem seu regime de verdade, sua 'política geral' de verdade". Ou seja, as modalidades discursivas que ela acolhe e faz funcionar como verdadeiros.

Ao articularmos tais dizeres com a pesquisa desenvolvida, é possível refletir que no CIPJC, o indígena é objetificado para que desse processo se constitua a subjetivação de seus traços étnico-culturais e, dessa forma, tem-se em circulação, no ciberespaço e na rede escolar, a representação de uma "verdade" do que é ser indígena, via olhar e voz do branco mais uma vez.

Por meio do embate entre línguas e sujeitos ocorrido nos espaços de enunciação, os sujeitos são (re)vestidos e suas identidades erigidas por agenciamentos enunciativos, configurados politicamente e vinculados aos saberes que alcançaram o caráter hegemônico e que integram o imaginário social. Essa vontade de verdade estabelece-se apoiada sobre um suporte e uma distribuição institucional, e tende a exercer sobre outros discursos uma pressão, um certo poder de coerção (FOUCAULT, 2013a, p. 17), dado pelo desejo da manutenção de uma fala fonocêntrica, obliteração da manifestação multifacetada da linguagem, suas infindáveis possibilidades de sentidos mediante a história (GOULART, 2003).

Existem práticas por meio das quais o sujeito é definido, transformado no seio da sociedade, a partir da formação de certos tipos de conhecimento via discurso. Segundo Foucault (2013b), somos impelidos à verdade, como uma obrigação, e a uma organização científica do conhecimento. Há um ponto de contato na forma como os indivíduos são manipulados e conhecidos pelo outro, ligada também ao modo como conhecem a si, uma espécie de governo de si e dos outros que ocorre via técnicas disciplinadoras e processos confessionais, situações das quais se erigem as identidades mediante às questões moralizantes da sociedade em dado momento histórico.

Diante disso, pode-se dizer que sendo a enunciação o discurso em processo, esta é o lugar por excelência da instauração do sujeito e da fabricação de discursos 
agenciadores de condutas, estratégias de vigilância, controle social (FOUCAULT, 2013b). No caso em análise, essa situação se dá via suporte das (novas) tecnologias. O discurso é uma prática que forma sistematicamente os objetos dos quais fala. Trata-se de um espaço de exterioridade em que se desenvolvem uma rede de lugares distintos (FOUCAULT, 2014, p. 66).

Assim, podemos dizer que o discurso é um espaço dotado de opacidade e que, por essa razão, não pode jamais ser analisado fora de suas condições de produção. Isso nos leva a compreender que o discurso, o sujeito e a produção da subjetividade são elementos marcados em constante processo de produção e de (trans)formação.

Nesse sentido, Bhabha (2013, p. 21) discorre que o homem, ao mesmo tempo em que é plural e híbrido, também é marcado pela inscrição cultural. A questão colonial deve ser pensada para além da lógica engessada dos binarismos (indígena/branco, incluído/excluído) e para além da oposição sujeito/objeto. Para esse autor, falar de cultura significa problematizar para além da oposição sujeito/cultura, no desejo de encaixes. É olhar o sujeito estranho, o marginalizado a partir de seu entre-lugar, sempre deslizante, não estável. Situação que nos instiga a analisar o material didático em questão para deslocar os sentidos e desejos de fixação de identidades, para além dos "inscritos na lápide fixa da tradição" (BHABHA, 2013, p.21).

Ao empreender a desestabilização das dicotomias na esfera ocidental, não podemos deixar de abordar Mignolo (2003) que discorre sobre a colonialidade do poder e da diferença colonial, ambas configuradas, historicamente, em uma geopolítica do conhecimento que privilegia poucos sujeitos localizados em determinados lugares geoistóricos do globo. Para esse autor, é preciso descolonizar o conhecimento, as formas de pensamento para além da clausura eurocêntrica. Em entrevista concedida à revista on-line Humanitas Unisinos, em 2013, explica que é necessário:

[...] abandonar a ideia universal de humanidade que nos foi imposta pelo Ocidente, modelada sobre o ideal imperial de "homem branco, heterossexual e cristão", e desfazê-la, para reconstruí-la na beleza e na incontrolável diversidade da vida, do mundo e dos conhecimentos.

A diferença colonial transforma diferenças em valores; por isso é uma estratégia fundamental, do passado e do presente, usada com vistas ao rebaixamento das populações e regiões do mundo. Disso entendemos que ainda não há outra maneira de 
se explicar como somos e pensamos senão via ancestralidade. Propondo uma interface com a $\mathrm{AD}$, verificamos que a história passou a discursivizar o indígena via espectro colonial, a formular práticas e a efetuar dizeres sobre ele em uma tessitura de escrituras superpostas, sempre (re)significadas. Consoante com as pesquisas empreendidas por Guerra (2015), até hoje os sujeitos indígenas estão submetidos a sansões sociais e legais que pouco permitem ouvir sua voz, favorecendo a construção de um imaginário social caraterizado por representações enviesadas.

O branco, em contato com as várias etnias indígenas, codificou e padronizou um conhecimento para si a partir do que elegeu ver no outro. Criou perfis de subjetividades, produziu a "invenção do outro". Processo construído e sancionado pela sociedade por meio da produção de discursos regulados, organizados e conjurados por estratégias de saber-poder (CASTRO-GÓMEZ, 2005). Essas relações se espalham por meio de mecanismos finos de controle na malha social, delineando o que pode ou não deve ser dito em relação a esses sujeitos, por meio de práticas disciplinares, viabilizadas pelo discurso, como um sistema de poder baseado no controle e submissão dos corpos, que Foucault (2013a) considera uma maneira de fazer história do presente, a partir dos termos do passado.

A construção dessa verdade sobre o que é ser indígena emerge nos ditos do CIPJC e apoia-se no campo tecnológico e cibernético, na ânsia de veicular e produzir saberes sobre os sujeitos e sobre a cultura na qual vivem. É possível observar a operacionalização dos modos de controle e de resistências subsidiados pela estratégia de poder-saber intersticialmente mobilizados nos jogos de publicização da vida privada das comunidades, a partir do material didático e da pedagogização midiática (FISCHER, 2002).

\section{Um gesto Analítico}

Como toda produção de sentido se dá pelo discurso e nele há, segundo Orlandi (2012), o confronto entre o simbólico e o político, asseveramos que o sujeito e linguagem são dotados de opacidade, uma vez que são atravessados por discursos outros em processos de memória que se formam e funcionam ideologicamente. Assim, podemos dizer que o discurso constitui-se, pelo já-dito que perpassa o campo social e formula-se, intradiscusivamente, deixando emergir na materialidade traços de subjetivação dos sujeitos conforme as formações discursivas em que se filia. 
Assim, na busca de levantar a historicidade e os possíveis efeitos de sentido que perpassam o fio intradiscursivo da materialidade eleita, o recorte $\mathrm{R} 3$, retirado da página 23 do guia didático CIPJC, mais especificamente do item "Retomando o fio da meada", nos leva a empreender um gesto de interpretação que seja capaz de desconfiar da vontade de verdade (FOUCAULT, 2013a) veiculada nesse dispositivo didático, perpassada pela voz do branco, no percurso de construção da identidade do indígena. Vejamos:

\begin{abstract}
R3: Eles já viviam aqui antes dos portugueses "descobrirem” o Brasil e antes até do Brasil se chamar Brasil. Por isso, são chamados, às vezes, de "os verdadeiros donos da terra". Mas apenas chamados, pois a realidade é que os índios têm brigado muito para ter suas terras reconhecidas. Aliás, suas terras e também a sua cultura, sua sabedoria, seus direitos. Talvez por não se conhecer a riqueza desses povos, suas histórias, a maneira como eles vivem e vêm o mundo. Nós vamos contar e mostrar aqui coisas sobre alguns desses povos pra você ficar conhecendo um pouco melhor como eles são. (Retomando o fio da meada, p. 23, grifos nossos)
\end{abstract}

Por meio da trama discursiva deste recorte extraído do dispositivo didático, produzido com subsídio das (novas) tecnologias e publicizado no ciberespaço, podemos observar o funcionamento do simbólico, na ordem da construção de um imaginário do e sobre o indígena como sujeitos ainda arraigados a representação colonialista que lhes negam historicidade e os apontam como seres à margem da cultura nacional (ORLANDI, 2008).

É possível ver em R3 o entrelaçamento de formações discursivas (FDs) - aquilo que pode ou deve ser dito a partir de uma certa região da formação social - de caráter colonial, capitalista e pedagógica. Tais FDs decorrem da menção do processo histórico de colonização por parte dos portugueses, da questão da demarcação territorial e do caráter pedagogizante, formatador da identidade do indígena que deve se fazer conhecida aos brancos em seu processo de escolarização por questões de cunho legal.

A construção da identidade desses sujeitos passa pela esfera da administração pública da subjetividade sempre controlada e contida para que signifique dentro dos moldes preconizados (DIAS, 2010). Por meio de designações, recategorizações, heterogeneidade constitutiva, utilização de pronomes possessivos, advérbios, locuções adverbiais, determinados verbos e expressões, é possível notar a emergência da representação estereotipada, marginal e excludente do/sobre o indígena por parte da 
cultura hegemônica por interesses econômicos e sociais que perpassam a história brasileira.

Explicamos: em primeira instância é-nos dado observar em R3 que o pronome pessoal do caso reto de terceira pessoa Eles é introduzido referencialmente como elemento de estreia textual demarcador do outro, para em seguida, ser recategorizado por meio da expressão "os verdadeiros donos da terra". O uso das aspas nessa expressão demarca a heterogeneidade constitutiva do discurso e sinaliza o discurso do outro, demonstrando que o sujeito-enunciador não deseja responsabilizar-se por esse dito por pertencer a outro espaço enunciativo (AUTHIER-RÉVUZ, 1998). Ainda nesse item, vê-se a ocorrência de ironia que, na esteira de Brait (1996), trata-se de uma manifestação discursiva relacionada à intertextualidade e a interdiscursividade, que faz emergir o contexto sócio-histórico de exclusão vivenciado pelos indígenas desde o início do processo colonial, com relação a usurpação territorial, bem como a luta pela restituição da terra. Isto é, apesar de serem os primeiros habitantes do território brasileiro ainda não possuem o direito à terra como algo reconhecido.

Prosseguindo a análise, posteriormente, são designados como os índios e por fim, esses povos; neste caso, a utilização do pronome demonstrativo junto ao substantivo faz emergir na materialidade uma fronteira cultural que, em lugar de aproximar, causa efeito de distanciamento entre os indígenas e a sociedade hegemônica.

Essa estratégia de progressão textual, que ocorre gradativamente para demarcar que é do outro que se fala, remete a questões históricas de exclusão referentes ao sujeito indígena que ecoam, interdiscursivamente. As inúmeras vozes precedentes atravessam o discurso pedagógico do Guia CIPJC, produzem dizeres que (re)avivam na memória um efeito de exclusão, de séculos de menosprezo, fruto do processo colonial vivenciado pelo Brasil em relação a Portugal. Em suma, a identidade de um sujeito constitui-se por meio da força de circulação de verdades, relações de poder advindas dos ecos de uma memória discursiva e de técnicas de persuasão que perpassam e constituem o indivíduo.

Os guias didáticos, no bojo das estruturas educacionais, surgem como objetos/instrumentos de uso do poder, cuja positividade permite governar, já que a governamentalidade se dá pela ordem do consentimento, do domínio da ação de seus corpos pelos outros (que na verdade refletem o poder), produzindo comportamentos e saberes que se articulam com um conjunto de dispositivos e estratégias capazes de subjetivar, ou seja, constituir/fabricar os sujeitos. Ao constituir o sujeito dessa forma, ao 
construir a própria identidade dos indivíduos, as redes de poder produzem indivíduos governáveis por meio de tecnologias de individualização e normalização.

Exemplos disso são os currículos escolares que são visualizados como uma invenção da modernidade, a qual envolve formas de conhecimento cujas funções consistem em regular e disciplinar o indivíduo que entrou na escola, sancionando socialmente o poder por meio da maneira pela qual (e as condições pelas quais) o conhecimento é selecionado, organizado e avaliado nas escolas. A construção da vida, com base na liberdade e na exigência de se ser governado em nome dessa noção, tornou-se alguma coisa de normal, natural: a vida e a subjetividade ocidental moderna não podem ser conceitualizadas fora da noção de liberdade. O sujeito ocidental moderno foi condenado a viver em liberdade, mesmo quando luta contra aquele que julga ser o seu maior oponente, o poder. Ou seja, o professor pensa ter liberdade para agir, mas é governado pelas normas do MEC/Estado.

O entendimento de Foucault acerca da liberdade é indissociável da noção de governamentalidade enquanto articulação sempre negociada, porque estratégica, entre tecnologias de poder, tecnologias de controle e tecnologias de resistência/ liberdade. O problema da governamentalidade moderna, nesta perspectiva, não se coloca tanto do lado da possibilidade de analisar o fenômeno do poder enquanto estado de dominação, mas, sobretudo, coloca-nos perante a possibilidade de criação de uma história que tenha por objeto as diferentes modalidades de autocompreensão e autoformação segundo as quais, na cultura ocidental, os seres humanos se tornam sujeitos, no caso, a subjetivação que se estuda é a dos indígenas.

Ao utilizar a locução verbal formada de verbo auxiliar mais o particípio, têm brigado, o sujeito enunciador traz à baila, novamente, a questão da luta pela terra empreendida pelos indígenas. Segundo Ferreira (2009), o sintagma verbal "brigar" significa: luta de braço, lutar, contender e disputar, ressaltando assim efeitos de sentido negativo. É possível problematizar a partir desse item lexical que o enunciador deixa escapar, por meio de um lapso, aqui compreendido como deslize da linguagem, de forma inconsciente, um dito em lugar de outro (AUTHIER-RÉVUZ, 1998): isto é, que considera os povos indígenas causadores frequentes de violência e contendas na busca pelos atributos legais que lhes deveriam ser conferidos.

Nessa esteira, observa-se que os sujeitos indígenas têm se mobilizado para solucionar a situação demarcatória de posse de terras, em um gesto de resistência com 
relação à cultura hegemônica, segundo o qual precisam "brigar" muito. Nota-se que o sintagma verbal, intensificado pelo advérbio, satélite do núcleo verbal (NEVES, 2011), faz emergir o sentido de que os indígenas incorrem disputas não-pacíficas pela posse do espaço físico e cultural no cenário nacional, na busca do reconhecimento dos direitos que lhes cabem.

Outros termos que nos chamam atenção são os advérbios de lugar, aqui e antes. O primeiro, funcionando como satélite do núcleo verbal "viviam", remete ao Brasil para delinear traços semânticos de lugar. Já o segundo, que significa tempo ou lugar anterior, conforme Ferreira (2009), aparece no fragmento por duas vezes, possuindo relação de anterioridade não fórica, posposta por expressão complementar acompanhada de preposição "antes dos portugueses" e "antes até do Brasil" chamados, conforme o esquema sintático em que aparecem, de completáveis ou transitivos (NEVES, 2011). Ambos situam a condição do indígena como primeiro habitante das terras brasileiras, anterior ao advento da colonização portuguesa. Temos marcado aqui o desejo de (des) sedimentar o dito de que a história do país começa a partir de 1500, ao ser ocupado pelos portugueses via processo expansionista; ideia abalizada também pelo uso das aspas no sintagma verbal "descobrirem", conferidoras de ironia (BRAIT, 1996) e heterogeneidade constitutiva do discurso (AUTHIER-RÉVUZ, 1998).

Os pronomes possessivos seus e suas que acompanham os respectivos substantivos (terras, cultura, sabedoria, direitos, histórias) instituem um caráter de pertença que indicam parte ou peça de um todo referente ao um possuidor (NEVES, 2011). Isso permite veicular o efeito de sentido, marcado linguisticamente, de que o indígena é uma espécie de estrangeiro em sua casa (CORACINI, 2007), delineando-se um uma fronteira étnico-cultural entre o indígena, o sujeito-enunciador branco e o público alvo do CIPJC.

Nesse processo de se falar do imaginário que constrói a identidade do indígena em contraponto a identidade do branco, viabiliza-se o que Santiago Castro-Gómez (2005) denomina de a "invenção do outro". Tal material, considerado como um tipo de prática disciplinadora, cria perfis de subjetividade estatalmente coordenados legitimado pela escrita. A palavra escrita, nesse contexto, funciona como construtora de identidades, verdades, leis, planejadora de programas modernizadores, organizadoras da compreensão do mundo em termos de inclusões e exclusões. O Estado, enquanto apoiador financeiro e legal de tais iniciativas, (in)(en)forma o sujeito (DIAS, 2010), de modo que os indígenas continuam a serem considerados povos à margem, visto que 
estes sujeitos historicamente foram banidos de seus territórios e considerados como "bárbaros" que necessitavam do processo civilizatório colonial, a fim de se ocidentalizarem (CASTRO-GÓMEZ, 2005).

Ao se propor "contar e mostrar aqui coisas sobre alguns desses povos", o aparato pedagógico em análise adentra o cenário educacional por meio do amparo jurídico da lei $11.645 / 08$, definidora da obrigatoriedade educacional a respeito do conhecimento sobre as etnias indígenas do Brasil. Assim, materializa-se um perfil de subjetividade do indígena, por meio das práticas de poder-saber direcionadoras da construção de identidades atravessadas pelo preconceito, estereótipos e ideias limitadoras, tomadas como verdades absolutas (FOUCAULT, 2013a). Esse processo de apoio à diversidade cultural é, simultaneamente, inclusivo e excludente, uma vez que separa as pessoas e os espaços de acordo com as esferas e comportamentos sociais que possuem.

Em consequência, as crianças em idade escolar tendem a desconhecer a permanência e a contemporaneidade do índio e as questões atuais fora dos moldes estatizados pelo guia. Há o reforço da representação mítica de sua cultura que dificulta a compreensão do papel dos indígenas, hoje perpassado por outro tipo de colonialidade do poder que, segundo Mignolo (2003), remete às novas organizações das relações econômicas, políticas e sociais vinculadas ao capitalismo e a globalização.

Estamos vendo aparecer uma série de estratégias, tecnologias e táticas dirigidas que parecem constituir mais do que simples programas destinados à melhoria da escola pública, como propagam as pessoas envolvidas na produção e divulgação dessas políticas. São tecnologias para controlar o currículo e "administrar" ou "governar" os/as docentes. Foucault propõe ver o poder em sua positividade, como produtor de verdades, de conhecimento e de saber. Sobre isso ele diz: "Temos antes que admitir que o poder produz saber (e não simplesmente favorecendo-o porque o serve ou aplicando-o porque é útil); que poder e saber estão diretamente implicados; que não há relação de poder sem constituição correlata de um campo de saber, nem saber que não suponha e não constitua ao mesmo tempo relações de poder" (2013b, p.27).

\section{4. (A)final, algumas considerações}


Diante das considerações, da hipótese, das perguntas levantadas e dos objetivos traçados, o processo analítico da materialidade do CIPJC possibilita delinear efeitos de sentidos de exclusão que, embora seja enunciada no presente, apresenta uma representação do indígena que remete há séculos de desvalorização das culturas minoritárias, periféricas.

Além disso, da materialidade, pode-se denunciar, mediante a manifestação das FD pedagógica e FD colonial, a configuração de ideias limitadoras e preconceituosas, consolidadas pelo tempo e tomadas como verdades cristalizadas, imperando o que pode ou não ser dito pelos discursos vigentes, sob o fomento hegemônico que se apropria desses mecanismos didáticos para abordar assuntos sob a perspectiva in/excludente.

Essas representações, ainda que inconscientemente, reforçam o indígena como sujeito marginalizado, de cultura inferiorizada, e contribuem para a permanência de uma visão eurocêntrica de sua figura. São efeitos de sentido construídos e disseminados por estratégias de saber-poder, determinadas por relações de interesse do grupo que a produz e faz circular. A partir do que (d)enuncia nesse possível gesto de interpretação discursiva, o Guia didático surge como mais um, dentre os diversos dispositivos culturais civilizatórios que, na tentativa de incluir, promove a diferenciação e exclusão social.

Para nós, o Guia (re)produz ditos que contribuem para a cristalização de uma identidade ilusória sobre o indígena, perpassados pela vontade de verdade dos dizeres do sujeito-enunciador branco, que derivam de relações com discursos outros que possuem um papel preponderante nas projeções imaginárias ligadas à antecipação e à formulação do que é dito sobre o sujeito indígena. Ao constituir o sujeito dessa forma, ao construir a própria identidade dos indígenas, o poder moderno produz indivíduos governáveis por meio de tecnologias de individualização e normalização, ao mesmo tempo em que os silencia, e os "inclui" socialmente.

É preciso desconfiar de tais iniciativas, descolonizar o pensamento, descontruir visões eurocentristas, ocidentalistas que insistem em manter os indígenas na subalternidade, na periferia. Talvez não seja de interesse Estatal que o indígena esteja fora do jogo social, mas que signifique dentro de um determinado sistema de controle. As políticas públicas assistencialistas de inclusão da diversidade cultural, sob a ótica do capitalismo, produzem o efeito de sentido de ilusão de pertencimento ao sujeito indígena, no entanto, trata-se de um pertencimento altamente regulado pelas relações de poder. 
Diante disso, problematizamos que o dispositivo didático, na ânsia de incluir o indígena no cenário social, como um sujeito ativo e participante do contexto histórico, ratifica a exclusão e permita dar continuidade à posição pautada em um hiato, restabelecendo dois polos sociais cada qual vivendo "deste" e "do outro lado da linha"; em que o "outro lado", a outra cultura, é o lugar onde se encontram os sujeitos que vivem sob o prisma da desqualificação relegada pela sociedade logocêntrica que os impede de significar para além desse nicho social em que habitam.

\section{Referências}

ARAÚJO, Ana C. Z.; CARELLI, Rita; CARELLI, Vincent. Cineastas Indígenas para Jovens e Crianças - guia didático para estudantes do ensino. Olinda, PE: Vídeo nas Aldeias, 2010.

AUTHIER-RÉVUZ, Jacqueline. Palavras incertas: as não coincidências do dizer. Trad. Cláudia C. Pfeiffer et al. Campinas: Editora Unicamp, 1998.

BHABHA, Homi. O local da cultura. Trad. De Myriam Ávila, Eliana Lourenço de Lima Reis e Glaucia Ranete Gonçalves. Belo horizonte: Editora UFMG, 2003.

BRAIT, Beth. Ironia em Perspectiva Polifônica. Campinas, Editora Unicamp, 1996.

BRASIL. Lei 11.645, de 10 de marco de 2008. Disponível em: http://www.planalto.gov.br/ccivil_03/_ato2007-2010/2008/lei/111645.htm. Acesso em 22 maio 2016, às $13 \mathrm{~h}$.

CASTELLS, Manuel. A sociedade em rede. Trad. Roneide Venâncio Majer. 10 ed. São Paulo: Paz e Terra, 2007.

CASTRO-GÓMEZ, Santiago. Ciências sociais, violência epistêmica e o problema da "invenção do outro". In: LANDER, Edgardo (Org.). A colonialidade do saber: eurocentrismo e ciências sociais. Perspectivas latino-americas. Coléccion Sur Sur, Clacso, Ciudad Autónoma de Buenos Aires, Argentina, 2005. p. 169-186.

CORACINI, Maria J. A celebração do outro: arquivo, memória e identidade: línguas (materna e estrangeira). Plurilinguísmo e tradução. Campinas: Mercado das Letras, 2007.

COUTO, Edvaldo S. Narrativas pessoais nas redes sociais digitais. In: CORACINI, Maria J.; CARMAGNANI, Ana M.G. (Orgs). Mídia, Exclusão e Ensino: Dilemas e desafios n contemporaneidade. Campinas: Pontes, 2014, p. 281-295.

DIAS, Cristiane. Telecentros como políticas públicas de inclusão digital: da administração da vida na cidade. In: ORLANDI, Eni P. (Org.). Discurso e políticas públicas urbanas: a fabricação do consenso. Campinas: RG, 2010.

FERREIRA, Aurélio B. H. Miniaurélio: o minidicionário da Língua Portuguesa. 7. ed. Rio de Janeiro: Positivo, 2009.

FISCHER, Rosa M. B. O dispositivo pedagógico da mídia: modos de educar na (e pela) TV. Revista Educação e Pesquisa, São Paulo, n. 28, v. 1, jan-jun, 2002. p. 151-162. 
FOUCAULT, M. A ordem do discurso. 23. ed. Trad. Laura Fraga de A. Sampaio. São Paulo: Loyola, 2013a.

FOUCAULT, M. Vigiar e punir: nascimento da prisão. Trad. Raquel Ramalhete, 41 ed. Petrópolis, RJ: Vozes, 2013b.

FOUCAULT, M. Arqueologia do saber. 8. ed. Tradução de Luiz Felipe Neves. Rio de Janeiro: Forense Universitária, 2014.

FOUCAULT, M. Microfísica do poder. Tradução de Roberto Machado. Rio de Janeiro: Graal, 2015.

GUERRA. Vânia M. L. O indígena de Mato Grosso do Sul: práticas identitárias e culturais. São Carlos: Pedro \& João, 2010.

AUTHIER-RÉVUZ, Jacqueline. Povos indígenas: Identidade e Exclusão Social. Campo Grande: Editora UFMS, 2015.

GOULART, Audemaro T. Notas sobre o desconstrucionismo de Jacques Derrida. Programa de Pós-graduação em Letras, Belo Horizonte: Editora PUC Minas, 2003, p. 01-29.

LÈVY, Pierry. As tecnologias da inteligência. Trad. Carlos I. da Costa. São Paulo; 34, 1993.

LIMBERTI, Rita P. A identidade em situação de contato intercultural. Revista Raído, Dourados (MS), vol 2, n.4, jul/dez 2008, p. 9-19.

LIMBERTI, Rita P. Discurso indígena: aculturação e polifonia. Dourados: Editora UFGD, 2009.

LIMBERTI, Rita P. A Imagem do índio: discursos e representações. Dourados: Editora UFGD, 2012.

NEVES, Maria H. Gramáticas de usos do Português. 2 ed. São Paulo: Editora Unesp, 2011.

ORLANDI, Eni P. Terra à vista - discurso do confronto: velho e novo mundo. 2 ed. Campinas: Editora Unicamp, 2008.

ORLANDI, Eni P. Discurso e texto: formulação e circulação dos sentidos. 4 ed. Campinas: Pontes, 2012.

PÊCHEUX, Michel. A Semântica e Discurso: uma crítica a afirmação do óbvio. Tradução de Eni Orlandi et. al. Campinas: Editora Unicamp, 1988.

PÊCHEUX, Michel; FUCHS, Catherine. A propósito de uma análise automática do discurso: atualização e perspectivas. In: GADET, Françoise; HAK, Tony. Por uma análise automática do discurso: uma introdução à obra de Michel Pêcheux. Trad. Betânia Maria et. al. Campinas: Editora Unicamp, 1997, 163-252.

PÊCHEUX, Michel. O discurso: estrutura ou acontecimento. Tradução de Eni Puccinelli Orlandi. 6 ed. Campinas: Pontes, 2012.

MARQUES, Cinthia N.; SOUZA, Claudete C. Memória terena: história e língua, educação escolar e cultura, identidade e resistência. 2008. Disponível em: $<$ http://www.propp.ufms.br/gestor/titan.php?target=openFile\&fileId=382>. Acesso em: 25 jan. 2016 às $19 \mathrm{~h}$. 
MIGNOLO, Walter D. Histórias locais/ projetos globais: colonialidade, saberes subalternos e pensamento liminar. Tradução de Solange Oliveira. Belo Horizonte: Editora UFMG, 2003.

MIGNOLO, Walter D. Deocolonialidade como caminho para cooperação. Revista do Instituto Humanitas Unisinos, n. 431, ano XIII. Entrevista concedida a Luciano Gallas. Tradução de André Langer em 04-11-2013. Disponível em: $<\mathrm{http}$ ://www.ihuonline.unisinos.br/index.php?option=com_content\&view=article\&id=5 $253 \&$ secao $=431>$. Acesso em: 25 abr. 2016, às $22 \mathrm{~h}$.

Data de Recebimento: 15/02/2018

Data de Aprovação: 07/06/2018 


\title{
Para citar essa obra:
}

MOREIRA, Icléia Caires; GUERRA Vânia Maria Lescano. Um olhar discursivo sobre o processo de subjetivação do indígena em dispositivo didático. In: RUA [online]. Volume 24, número 2 - p. 395-412 - e-ISSN 2179-9911 - novembro/2018. Consultada no Portal Labeurb - Revista do Laboratório de Estudos Urbanos do Núcleo de Desenvolvimento da Criatividade.

http://www.labeurb.unicamp.br/rua/

Capa: Detalhe da capa do livro Cineastas Indígenas para Jovens e Crianças - guia didático para estudantes do ensino.

\author{
Laboratório de Estudos Urbanos - LABEURB \\ Núcleo de Desenvolvimento da Criatividade - NUDECRI \\ Universidade Estadual de Campinas - UNICAMP \\ http://www.labeurb.unicamp.br/ \\ Endereço: \\ LABEURB - LABORATÓRIO DE ESTUDOS URBANOS \\ UNICAMP/COCEN / NUDECRI \\ CAIXA POSTAL 6166 \\ Campinas/SP - Brasil \\ CEP 13083-892 \\ Fone/ Fax: (19) 3521-7900 \\ Contato: http://www.labeurb.unicamp.br/contato
}

